\title{
Endolymphatic Therapy with Radioactive Gold for Malignant Melanoma
}

\author{
G. H. JANTET,* F.R.C.s.; J. M. EDWARDS,† F.R.C.s.; M. H. GOUGH,† F.R.C.S.; J. B. KINMONTH,§ M.S., F.R.c.s.
}

Brit. med. F., 1964, 2, 904-906

This is an account of the clinical results achieved in a group of patients with malignant melanoma who were treated by excision of the primary tumour and direct injection of radioactive materials into the lymph vessels and thence into the regional nodes. The results in patients followed up to five years have been encouraging. This paper is a fuller account of the communication made to the Twentieth Meeting of the Surgical Research Society in May 1964. Earlier reports on this method have been made by Jantet $(1958,1962)$ and Jantet et al. (1964).

\section{Details of Patients}

Thirteen patients with malignant melanoma have been treated by this method, using radioactive gold. Twelve had a histologically proved malignant melanoma of the skin without distant metastases clinically or radiologically. The regional lymph nodes were clinically normal. One patient had a clinically suspicious node and also multiple skin metastases on the same leg and thigh as the primary lesion. Details of the patients are shown in Table I.

TABLE I.-Patients Treated with Endolymphatic Injection of Radioactive

\begin{tabular}{|c|c|c|c|c|c|c|}
\hline \\
\hline $\begin{array}{l}\text { Case } \\
\text { No. }\end{array}$ & Sex & $\begin{array}{c}\text { Age } \\
\text { in } \\
\text { Years }\end{array}$ & Site of Lesion & $\begin{array}{c}\text { Site of } \\
\text { Injection }\end{array}$ & $\begin{array}{l}\text { Dose } \\
\text { (mc.) }\end{array}$ & $\begin{array}{l}\text { Volume } \\
\text { Given } \\
\text { (ml.) }\end{array}$ \\
\hline $\begin{array}{r}1 \\
2 \\
3 \\
4 \\
5 \\
6 \\
7 \\
8 \\
9 \\
10 \\
11 \\
12\end{array}$ & $\begin{array}{l}\mathrm{M} \\
\mathrm{F} \\
\mathrm{F} \\
\mathrm{M} \\
\mathrm{M} \\
\mathrm{F} \\
\mathrm{F} \\
\mathrm{F} \\
\mathrm{F} \\
\mathrm{F} \\
\mathrm{M} \\
\mathrm{F}\end{array}$ & $\begin{array}{l}44 \\
35 \\
66 \\
42 \\
37 \\
53 \\
33 \\
35 \\
73 \\
49 \\
48 \\
22\end{array}$ & $\begin{array}{l}\text { L 3rd finger } \\
\text { L calf } \\
\text { R ankle } \\
\text { R knee } \\
\text { R 4th finger } \\
\text { L calf } \\
\text { L calf } \\
\text { R hallux } \\
\text { R leg } \\
\text { L knee } \\
\text { L forearm } \\
\text { Trunk, dorsal }\end{array}$ & $\begin{array}{l}\text { Dorsum wrist } \\
\text { Leg } \\
\text { Leg } \\
\text { Leg } \\
\text { Wrist } \\
\text { Calf } \\
\text { Calf } \\
\text { Ankle } \\
\text { Foot } \\
\text { Foot } \\
\text { Arm } \\
\text { Arms }\end{array}$ & $\begin{array}{l}25 \\
31 \\
50 \\
56 \\
16 \\
51 \\
42 \\
26 \\
37 \\
70 \\
40 \\
64\end{array}$ & $\begin{array}{l}2 \\
0.75 \\
0.25 \\
1.0 \\
1.0 \\
1.1 \\
0.9 \\
4.5 \\
2.0 \\
1.0 \\
2.4 \\
2.8\end{array}$ \\
\hline 13 & $\mathrm{~F}$ & 59 & $R$ reg1 & Ankle & 41 & 1.6 \\
\hline
\end{tabular}

\section{Treatment}

When the lesion was on a finger or toe ( 3 patients), the digit was disarticulated at the metacarpophalangeal or metatarsophalangeal joint. At other sites a wide and deep excision was carried out (10 patients), and in all the patients except one the defect had to be covered by a skin graft.

As soon as histological confirmation of the diagnosis had been obtained the efferent lymphatic pathway draining the site of the primary was injected with radioactive colloidal gold $\left({ }^{198} \mathrm{Au}\right)$. No prophylactic block-dissection of the draining lymph nodes was performed.

* Formerly Lecturer and Research Assistant, Department of Surgery, St. Thomas's Hospital Medical School, London. Present address: St. Mary's Hospital, Paddington.

t Lecturer and Research Assistant, Department of Surgery, St. Thomas's Hospital Medical School, London.

‡ Senior Registrar, Department of Surgery, St. Thomas’s Hospital Medi-

cal School, London.
Professor of Surgery, Department of Surgery, St. Thomas's Hospital Medical School, London.

\section{Technique of Endolymphatic ${ }^{198} \mathrm{Au}$ Injection}

The basic technique was similar to that used for diagnostic injections and has been described fully elsewhere (Kinmonth et al., 1962). To outline the lymphatic pathways an injection of the coloured dye patent blue violet was made in the subcutaneous tissues around the site of the primary malignant melanoma. The dye was taken up by the lymphatic vessels and coloured them bluish green so that they might be seen through the skin. They were then exposed, and, depending on the number present, one or several of them were injected with the ${ }^{198} \mathrm{Au}$.

In those patients in whom a pre-operative histological diagnosis had been obtained the intralymphatic injection of ${ }^{198} \mathrm{Au}$ was made immediately after the primary excision and the patent blue violet was injected under and around the primary lesion. In the other patients in whom histological confirmation of the diagnosis was obtained from the whole lesion after it had been excised the patent blue violet was injected circumferentially in the margins of the grafted area or at the amputation site in the case of a finger or toe. In some cases it was found best to inject patent blue violet interdigitally and make the endolymphatic gold injection near the digits.

Primary lesions on the trunk are also suitable for this technique but may present more difficulties in demonstrating the efferent lymphatics ; in some cases it may be easier to reach the draining nodes indirectly by injecting an arm or leg lymphatic, although this is clearly a less satisfactory approach. This had to be done in one of our patients whose lesion was in the middle of the back and drained to both axillae.

A giving-set of needle and plastic tubing, similar in principle to that described by Rutt et al. (1964), connected to the syringe containing gold, was used.

\section{Volume}

To obtain a high concentration of activity in the nodes the calculated dose of ${ }^{198} \mathrm{Au}$ was given slowly over about five minutes. The volume of the colloidal gold solution injected has usually ranged from 0.25 to $2.8 \mathrm{ml}$. In some of the later patients in the series the first part of the injection was given slowly but the last half or one-third of the dose was injected as rapidly as possible in order to produce more extravasation of the solution through the walls of the lymph trunks. This was done in particular in one patient (Case 9) who, as described below, differed from the others in having multiple recurrent skin nodules. In Case 8 the final one-third of the dose was diluted in saline and injected rapidly, so that a total of $4.5 \mathrm{ml}$. was given. It has been our policy with subsequent patients to use a larger volume, injecting the latter part of it rapidly in order to produce more extravasation in the limb lymphatics.

\section{Dose}

The radioactive colloidal gold used $^{1}$ had a physical half-life of 2.69 days. The size of the particles ranged from less than

${ }^{1}$ Obtained from the Radiochemical Centre, Amersham, Bucks. 
$50 \AA$ to about $225 \AA$, the overall mean being $66 \AA$. Most of the radioactivity was carried by those in the 100 to $125 \AA$ range.

The dose required was calculated from the beta-particle dosimetry formula given by Hine and Brownell (1956). The same formula can of course be used to calculate the dose actually received by the nodes in patients in whom it might be possible to remove the nodes, weigh them, and measure their radioactivity. In a previous publication (Jantet, 1962) we described the results in two patients in whom the nodes could be removed, weighed, and their activity measured. After injections of 30 $\mathrm{mc}{ }^{198} \mathrm{Au}$ into each leg, estimated levels of 26,500 and 35,000 rads were obtained in certain selected points in the excised inguinal nodes. These findings suggested that a high concentration of gold and strong selective internal irradiation can be obtained in the lymph nodes.

The $\beta$-dose formula must be regarded as giving the maximum $\beta$-dose for the concentration of isotope obtained. The dose to specific parts of the lymphatic system will in general be lower than this, particularly for volumes of tissue which are of small dimensions compared with the maximum $\beta$-particle range (about $5 \mathrm{~mm}$.). For all lymphatic tissues the dose will tend to fall off at the periphery compared with the centre.

$\gamma$-dose makes a small contribution and may be ignored, as it may also in relation to radiation necrosis.

The calculation requires a knowledge of the weight of the tissue to be irradiated. The total weight of lymphoid tissue in the body (including the spleen) has been estimated as about $1 \%$ of the total body weight (Yoffey and Courtice, 1956). From this we made a rough estimate of the weights of the inguino-ilio-aortic nodes as $85 \mathrm{~g}$. and the axillary nodes as 50 g. on each side for a 70-kg. adult.

At first, radiation levels in the lymph nodes of about 20,000 rads were aimed at, but this level was gradually raised, and in later patients levels of about 70,000 rads were the aim. The quantity of ${ }^{198} \mathrm{Au}$ injected therefore varied from $16 \mathrm{mc}$ in the early patients to $70 \mathrm{mc}$ in later patients. The figures obtained can only be approximate, but are nevertheless useful as a guide to the quantity of ${ }^{198} \mathrm{Au}$ required for the injection.

\section{Distribution of Injected Gold}

External scanning of the patients following injections showed the radioactivity to be concentrated along the lymph vessels and nodes draining the primary site. After injections in the lower extremity the maximum activity usually lay in the ilioinguinal or paravertebral nodes. Some patients showed concentration of activity in nodes near the termination of the thoracic duct. Diagrams typical of the distribution have been published (Jantet, 1962).

\section{Follow-up}

The follow-up of the 13 patients, all of whom are surviving, is shown in Table II. The period of follow-up is from $1 \frac{1}{2}$ to 5 years. None of the 13 patients has developed lymph-node metastases ; 11 patients are alive and free from recurrence or

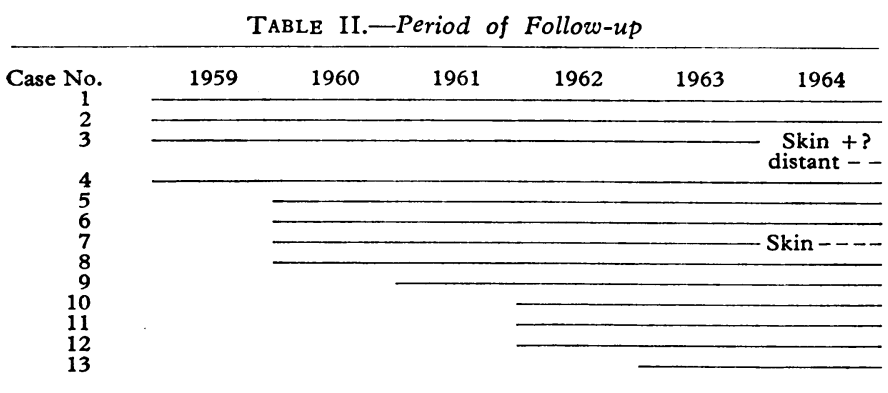

metastasis ; 2 patients who developed recurrences are discussed more fully, as they are of interest.

After wide excision and grafting of a primary on the calf four years previously, one patient (Case 7) developed a single nodular recurrence $1 \mathrm{~cm}$. in diameter, $10 \mathrm{~cm}$. above the site of the primary excision. There were no other metastases. The recurrence was widely excised and an inguinal-node block dissection was carried out together with an intra-arterial perfusion with phenylalanine mustard. Histological examination, however, showed no metastases in the nodes, which had very marked fibrosis interpreted as being the result of irradiation by the ${ }^{198} \mathrm{Au}$. Particles which had the staining characteristics of gold were still present in the nodes. In retrospect it is thought that a greater volume of gold solution should have been injected more rapidly in this patient to produce some extravasation and greater irradiation of the lymphatic vessels. This might have prevented the growth of the solitary nodule four years later.

The second patient (Case 3) had a malignant melanoma just below the lateral malleolus. This drained to the inguinal and the popliteal pathways, and both were therefore injected. The injection into the inguinal pathway, however, was not entirely satisfactory technically. The patient developed some small nodules near the site of this unsatisfactory injection four years later. They were excised. She has recently also developed a single nodule in the skin of one breast. It is uncertain whether this is a new primary or distant metastasis. Again in this patient the recurrence was on the lymphatic pathways of a limb and associated with an insufficient injection.

An instructive result was obtained in one patient (Case 9), who was different from the others. She had multiple deposits in the skin of the same leg and thigh and a clinically suspicious inguinal node four years after excision of a primary on the foot. A solution containing $37 \mathrm{mc}$ of radioactive gold in a volume of $2 \mathrm{ml}$. was injected rapidly into a foot lymphatic in order to obtain maximum diffusion out of the lymphatics; the nodules became red and swollen and then disappeared, as did the inguinal node; a larger nodule underwent radionecrosis; the area had to be excised and grafted. She remains well and free from recurrence after three years.

\section{Other Patients}

During the period 1957-63, in our clinical practice, we encountered eight other patients with a primary malignant melanoma of a limb or of the trunk, with clinically normal lymph nodes and no distant metastases, who were treated on a plan conventional in the past. This consisted of wide and deep excision of the primary without endolymphatic therapy and without prophylactic node-dissection. These patients were not selected in any way and were not intended to represent a control group. The reason they did not receive any endolymphatic gold was either because none was available at the time or because it was refused. It is interesting to note that seven out of these eight patients developed lymph-node or more distant recurrences within one to three years from the primary treatment, and six have died.

\section{Complications}

Two complications have been encountered. One patient had a temporary depression of the bone-marrow from which she made a full recovery ; she had previously been heavily irradiated for a lymphosarcoma of one adenoid. Another patient (Case 9) developed a $2.5-\mathrm{cm}$. area of radionecrosis of the skin at the site of injection of the gold following leakage-this had to be excised and the defect grafted.

Although none of the patients has complained of it, on close questioning three of them admit to having mild oedema of the ankle of the injected leg at the end of the day. None has 
required any treatment and the oedema is not progressive. It is probably secondary to fibrotic changes in the nodes following the gold injection.

\section{Discussion}

The treatment of malignant melanoma, particularly in cases where there is no clinical evidence of metastasis-what might be termed "stage I" cases-has been difficult to plan in the past. Fortner et al. (1964) have performed routine block dissection of regional lymph nodes after removing the primary. They found that $38 \%$ of these patients had microscopical evidence of node involvement. Others have hesitated to perform routine prophylactic block dissections in the absence of clinical evidence of involvement. Wound-healing is poor after block dissection and the incidence of wound sepsis is high. There is inevitable deformity and scarring and very often severe lymphoedema. Indeed, many patients decline to have such an operation. An alternative plan of management is to excise the primary and wait to see if nodes become clinically involved before performing block dissection. This avoids a proportion of unnecessary operations but almost certainly leads to poorer results in the patients who do develop node metastases.

Another disadvantage of surgical treatment is the difficulty of dealing with the possible growth of secondaries in the lymphatics intervening between the primary lesion and the regional nodes, for it is only occasionally possible to excise primary and nodes in a single block. Irradiation of this block of tissue by conventional external methods only, even by supervoltage $x$-ray or cobalt gamma-ray, to the high dosage required for destruction of these malignant cells, is often impossible without the risk of widespread radiation morbidity. This might require extensive surgical excision to repair. This complication does not occur in endolymphatic therapy; the high dose is concentrated in the lymphatics, and, as has been shown, radionecrosis, should it occur, is localized and presents a relatively minor surgical problem.

It will be seen, therefore, that an alternative to block dissection would be very desirable if an effective one could be found. Endolymphatic therapy on the principle described here seems to offer such an alternative. The clinical results in this small group of patients seem sufficiently promising to warrant a larger scale trial on a statistical basis. This is particularly so as there have been considerable improvements in technique since this trial started five years ago.

Endolymphatic therapeutic injections may be combined with surgery or external irradiation in various ways, particularly for more advanced cases, but discussion of this is outside the scope of the present review.

\section{Conclusions}

Thirteen patients with malignant melanoma have been treated by excision of the primary and subsequent injection of radioactive gold particles into the lymphatics of the region.

The aim of the endolymphatic injection has been to treat possible metastases in the draining lymph vessels and in the regional nodes.

A review of these patients followed up to five years after treatment is encouraging and warrants further trial of endolymphatic therapy.

We wish to thank Dr. J. A. Fleming for his help and advice in this work. Four patients were treated while one of us (G. H. J.) worked in the Surgical Unit, St. Mary's Hospital, and we thank Professors C. G. Rob and W. T. Irvine for help with these. We are indebted to Dr. T. Gimlette and to the Radioisotope Departments of St. Thomas's Hospital and of St. Mary's Hospital for help with physical measurements. We would also like to thank Dr. W. F. Clapham for his help, particularly with the dosimetry.

\section{REFERENCES}

Fortner, J. G., Booher, R. J., and Pack, G. T. (1964). Surgery, 55, 485. Hine, G. J., and Brownell, G. L. (1956). Radiation Dosimetry, Academic Press, New York.

Jantet, G. H. (1958). 9th Scientific Meeting, Surgical Research Society, London.

(1962). Brit. 7. Radiol., 35, 692.

Kinmonth, J. B., Edwards, J. M., and Gough, M. H. (1964). Brit. 7. Surg., 51, 70 .

Kinmonth, J. B., Rob, C. G., and Simeone, F. A. (1962). Vascular Surgery. Arnold, London.

Rutt, D. L., Gough, M. H., and Kinmonth, J. B. (1964). Lancet, 1, 475.

Yoffey, J. M., and Courtice, F. C., (1956). Lymphatics, Lymph and Lymphoid Tissue, 2nd ed. Arnold, London.

\title{
Eczema Vaccinatum
}

\author{
P. W. MONCKTON COPEMAN,* M.A., M.B., M.R.C.P. ; H. J. WALLACE,* M.A., M.D., F.R.C.P.
}

When generalized vaccinia occurs in a patient with eczema the disorder is known as eczema vaccinatum, a grave and sometimes fatal illness. The characteristic rash of profuse vaccinial lesions, particularly dense in eczematous areas, is sometimes known as Kaposi's varicelliform eruption. Since, however, a clinically indistinguishable eruption and illness may be caused by herpes simplex in an eczematous subject, the terms eczema vaccinatum and eczema herpeticum are more exact.

Eczema vaccinatum is usually distinguishable from eczema herpeticum by the history, although for diagnosis virological studies may be necessary. In generalized vaccinia in noneczematous subjects the systemic upset is usually less severe and the eruption is more scattered. The variolas, modified smallpox, varicella, and erythema multiforme occasionally mimic eczema vaccinatum.

* St. Thomas's Hospital, London.
We report a study of eczema vaccinatum based on records made in the first few months of 1962 during the mass smallpox vaccination in England and Wales. Of chief interest were the incidence and mortality of the disease in relation to the following: age and sex ; source of infection, whether accidental or intended; type and activity of the underlying eczema. Other matters for inquiry were whether the infection followed primary vaccination or revaccination, virulence of specific batches of vaccine, and value of antivaccinial gamma-globulin and other treatments.

Our information came mainly from three sources. First, a questionary was sent to all consultant dermatologists in England and Wales; nearly all replied. Second, the Ministry of Health, from information supplied by medical officers of health, smallpox consultants, general practitioners, and other sources, made available to us 50 eczema vaccinatum case histories, including 